Editorials represent the opinions of the authors and not

necessarily those of the BMJ or BMA

\title{
Sudden cardiac death in young athletes
}

\section{Evidence supports a systematic screening programme before participation}

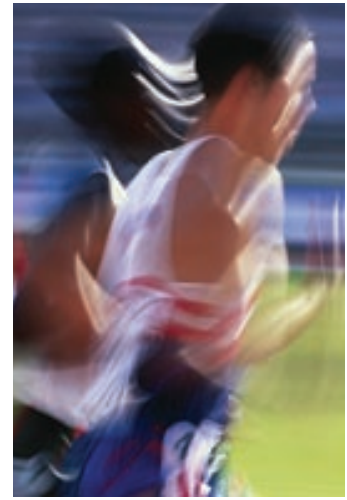

RESEARCH, p 88

Jonathan A Drezner associate professor, Department of Family Medicine, University of Washington, Seattle, WA 98195, USA

jdrezner@fammed.washington.edu Karim Khan associate professor, Centre for Hip Health and Mobility and Department of Family Practice, University of British Columbia,

Vancouver, Canada

Competing interests: JD is on the Medical Advisory Board for Parent Heart Watch and the Medical and Scientific Advisory Board for the Sudden Cardiac Arrest Association. $\mathrm{He}$ is on the Scientific Advisory Board for Heart Screen America, in which he has the option to own shares, but currently owns no shares and receives no other financial reimbursement.

Provenance and peer review: Commissioned; not externally peer reviewed.

Cite this as: BMJ 2008;337:a309 doi: 10.1136/bmj.a309
Which screening strategy should be used to identify young athletes at risk for sudden cardiac death is a highly controversial matter. For many years the medical community has disputed the cost effectiveness, feasibility, and accuracy of including 12 lead electrocardiography in the cardiovascular screening of athletes. Discordant recommendations from the American Heart Association and the European Society of Cardiology have fuelled a global debate about the usefulness of such screening in athletes. ${ }^{1}$ In the linked study, Sofi and colleagues analyse data from 30065 Italian athletes who underwent a complete pre-participation cardiovascular evaluation including resting and exercise electrocardiography. ${ }^{3}$

Sudden cardiac death in young athletes ( $<35$ years) is caused by a diverse set of structural diseases of the heart (such as cardiomyopathies) and electrical defects (such as ion channelopathies). In the United States alone, one young competitive athlete dies every three days from an unrecognised cardiovascular disorder. ${ }^{4}$ American and European authorities have recommended a comprehensive pre-participation evaluation, which includes a detailed patient and family history and a physical examination, in all athletes of 12 years or more. ${ }^{12}$

Warning symptoms of underlying cardiovascular disease-exertional chest pain, syncope or near syncope, palpitations, excessive dyspnoea, and unexplained seizures-warrant cessation of sports activity pending the results of diagnostic tests. A family history of sudden unexplained death or sudden death before the age of 50 as a result of cardiac problems may also indicate the presence of a genetic cardiovascular disorder. Unfortunately, standardised questionnaires developed to help healthcare providers perform a comprehensive pre-participation evaluation are underused. ${ }^{5}$ Thus, important elements of the athlete's history often go unrecognised.

A substantial challenge to screening is that apparently healthy asymptomatic athletes may have unsuspected cardiovascular disease-death is the first clinical manifestation of cardiac disease in up to $60-80 \%$ of athletes with sudden cardiac death. ${ }^{6}$ To date, no study monitoring sudden cardiac death has shown that a pre-participation evaluation based on history and physical examination can prevent or detect athletes at risk for sudden death.

The value of adding non-invasive cardiovascular tests such as electrocardiography to the screening process in athletes is widely debated. In 2007, the American Heart Association reaffirmed its recommendations against universal electrocardiographic screening in athletes, citing a low prevalence of disease, poor sensitivity, high false positive rate, poor cost effectiveness, and a lack of clinicians to interpret the results. ${ }^{1}$

In contrast, the European Society of Cardiology, International Olympic Committee, and the governing associations of several US and international professional sports leagues endorse the use of electrocardiography in the pre-participation screening of athletes. ${ }^{2}$ These recommendations are supported by studies showing that electrocardiography is more sensitive than history and physical examination alone at identifying athletes with underlying cardiovascular disease. ${ }^{7-10}$ In 1998, one study found that electrocardiography had a 77\% greater power than history and physical examination to detect hypertrophic cardiomyopathy. ${ }^{9}$ In 2006 , another study reported data from a national pre-participation screening programme in Italy in 42386 athletes over 25 years. ${ }^{8}$ It found that disqualification on the basis of a standardised history, physical examination, and electrocardiography produced a 10-fold reduction in the incidence of sudden cardiac death in young competitive athletes, and an $89 \%$ reduction of sudden cardiac death as a result of cardiomyopathy. ${ }^{8}$ Although only $0.2 \%$ of athletes were disqualified for potentially lethal cardiovascular conditions, the study reported a $7 \%$ false positive rate and a $2 \%$ overall disqualification rate. ${ }^{8}$ This raised concerns that adopting such a programme would lead to an unacceptable number of disqualifications in athletes with low risk of sudden cardiac death.

Recent studies have refined the electrocardiography criteria used to distinguish normal from abnormal results-producing lower false positive rates. ${ }^{10-12} \mathrm{~A}$ study of 2720 athletes and physically active schoolchildren in the United Kingdom reported that only $1.5 \%$ of those screened had a positive electrocardiogram. ${ }^{10}$ Another study reported preliminary findings of electrocardiographic screening in 9125 young adults (age 14-18) from the US and found that only $2 \%$ of tests were abnormal. ${ }^{11}$ These studies indicate that electrocardiographic screening in athletes results in an acceptable proportion of abnormal findings that can be of clinical significance.

The combined disease prevalence of all cardiovascular disorders that predispose young athletes to sudden cardiac death is around $0.3 \%(1 / 333) .{ }^{1}$ This estimate is confirmed by several studies using electrocardiographic screening in athletes with reported true positive rates of $0.2-0.4 \% .^{78} 10$ The consistency of these results across several studies in three different countries suggests that such screening may have similar value in different populations.

An important element of Sofi and colleagues' study is that only a small proportion $(1.2 \%)$ of athletes had 
distinct abnormalities identified on resting electrocardiography. As a result, false positives were few. Importantly, 153 of the 159 true positives involving athletes ultimately disqualified from sport with an identified cardiovascular disorder would have been overlooked on history and physical examination alone. ${ }^{3}$ Thus, although a detailed personal and family history and physical examination will detect an important but limited number of athletes with underlying cardiovascular disease, adding electrocardiography to the screening process will detect more athletes with silent cardiovascular disorders at risk of sudden death.

The existing evidence supports a systematic preparticipation screening programme for all competitive athletes, using a comprehensive personal and family history questionnaire, physical examination, and screening electrocardiography to identify those at risk.

1 Maron BJ, Thompson PD, Ackerman MJ, Balady G, Berger S, Cohen D, et al. Recommendations and considerations related to preparticipation screening for cardiovascular abnormalities in competitive athletes: 2007 update: a scientific statement from the American Heart Association Council on Nutrition, Physical Activity, and Metabolism: endorsed by the American College of Cardiology Foundation. Circulation 2007;115:1643-55

2 Corrado D, Pelliccia A, Bjornstad HH, Vanhees L, Biffi A, Borjesson M, et al. Cardiovascular pre-participation screening of young competitive athletes for prevention of sudden death: proposal for a common European protocol. Consensus statement of the study group of sport cardiology of the Working Group of Cardiac Rehabilitation and Exercise Physiology and the working group of myocardial and pericardial diseases of the European Society of Cardiology. Eur Heart J 2005;26:516-24.

3 Sofi F, Capalbo A, Pucci N, Giuliattini J, Condino F, Alessandri F, et al. Cardiovascular evaluation, including resting and exercise electrocardiography, before participation in competitive sports: cross sectional study. BM/ 2008;337:a346.

4 Maron BJ, Doerer JJ, Haas TS, Tierney DM, Mueller FO. Profile and frequency of sudden death in 1463 young competitive athletes: from a 25 year US national registry: 1980-2005. Circulation 2006;114:830.

5 American Academy of Family Physicians, American Academy of Pediatrics, American College of Sports Medicine, American Medical Society for Sports Medicine, American Orthopaedic Society for Sports Medicine, Medicine American Osteopathic Academy of Sports Medicine. Preparticipation physical evaluation. 3rd ed. New York: McGraw-Hill, 2005. http://amssm.org/ppehistory.pdf.

6 Maron BJ, Shirani J, Poliac LC, Mathenge R, Roberts WC, Mueller FO. Sudden death in young competitive athletes. Clinical, demographic, and pathological profiles. JAMA 1996;276:199-204.

7 Fuller CM, McNulty CM, Spring DA, et al. Prospective screening of 5,615 high school athletes for risk of sudden cardiac death. Med Sci Sports Exerc 1997;29:1131-8.

8 Corrado D, Basso C, Pavei A, Michieli P, Schiavon M, Thiene G. Trends in sudden cardiovascular death in young competitive athletes after implementation of a preparticipation screening program. JAMA 2006;296:1593-601

9 Corrado D, Basso C, Schiavon M, Thiene G. Screening for hypertrophic cardiomyopathy in young athletes. N Engl I Med 1998;339:364-9.

10 Wilson MG, Basavarajaiah S, Whyte GP, Cox S, Loosemore M, Sharma $\mathrm{S}$. Efficacy of personal symptom and family history questionnaires when screening for inherited cardiac pathologies: the role of electrocardiography. Br J Sports Med 2008;42:207-11.

11 Nora M, Zimmerman F, Ow P, Fenner P, Marek J. Preliminary findings of ECG screening in 9,125 young adults [abstract]. Circulation 2007;116:845.

12 Pelliccia A, Culasso F, Di Paolo FM, Accettura D, Cantore R, Castagna $W$, et al. Prevalence of abnormal electrocardiograms in a large, unselected population undergoing pre-participation cardiovascular screening. Eur Heart/ 2007;28:2006-10.

\section{Imported malaria in the UK}

\section{Is rising because of failure to comply with prophylaxis or to seek travel health advice}

\section{RESEARCH, p 103}

\section{Jane N Zuckerman director o}

WHO collaborating centre for

reference, research, and training in

travel medicine, Academic Centre

for Travel Medicine and Vaccines,

Royal Free and University College

Medical School, London NW3 2PF

j.zuckerman@medsch.ucl.ac.uk

Competing interests: JNZ has

been reimbursed by several

manufacturers of vaccines

and antimalarial prophylaxis-

including GlaxoSmithKline

Novartis, Sanofi Pasteur, SBL

Vaccines, and Wyeth-for

attending conferences, running

educational programmes, and

undertaking clinical trials. She

has also received unrestricted

educational grants

Provenance and peer review:

Commissioned; not externally

peer reviewed.

Cite this as: $B M / 2008 ; 337: a 135$ doi: 10.1136/bmi.a135
Malaria is endemic in more than 105 countries. With travel predicted to grow to nearly 1.6 billion international arrivals by 2020, travellers will be at increased risk of exposure. ${ }^{12}$ The linked observational study by Smith and colleagues substantiates the public health concerns regarding the prevention of malaria in migrant families in the United Kingdom. ${ }^{34}$ The authors report that cases of imported malaria significantly increased between 1987 and 2006, with an increasing proportion attributable to Plasmodium falciparum rather than Plasmodium vivax.

The increase in cases of imported malaria is not unexpected. It reflects the increase in the number of visits abroad by UK residents-70.5 million in 2007-together with a $150 \%$ increase in UK residents travelling to malaria endemic areas during the past decade. ${ }^{5}$ One notable change is that with improved vector control in Asia, most cases are now acquired in Africa. As severe acute respiratory syndrome showed, 21 st century threats to global public health and travel are inextricably interlinked, and they present ready opportunities for the rapid spread of infectious disease. ${ }^{6}$

Although people visiting friends and relatives formed the largest group returning with malaria during 2007, business and holiday travel accounted for 5\% and 14\% of cases. ${ }^{4}$ People visiting friends and relatives are at par- ticular risk-despite a $12 \%$ fall in the number of malaria cases reported in UK travellers during 2007, 72\% of cases were in such people. ${ }^{4}$

European sentinel surveillance data and other studies worldwide have reported up to 10000 cases of imported malaria in industrialised countries as a result of international travel, with a case fatality of around $1 \%{ }^{89}$ The increase in cases in the UK reported by Smith and colleagues occurred despite the availability for decades of effective methods of malaria prevention. ${ }^{3}$ People visiting friends and relatives accounted for $64.5 \%$ of all reported cases of malaria, and travel to West Africa accounted for $76 \%$ of cases in this high risk group. ${ }^{3}$ Large clusters of $P$ falciparum cases were located in London, mirroring UK migrant demography. The sustained increase in migration to the UK has contributed to the increasing incidence of imported malaria, as more migrant families travel to countries of their ethnic origin, where malaria is endemic. The study probably underestimates the true burden of malaria in UK travellers, and unless migration patterns to the UK change, this can be expected to increase.

Failure to comply with prophylaxis or to seek travel health advice mostly explains the increased risk of exposure and cases of malaria in travellers, particularly those visiting friends and relatives. Historically, the problem 
for travel health practitioners recommending malaria prophylaxis for travel to Africa and Asia has been the adverse publicity regarding this treatment. In addition, many people visiting friends and relatives underestimate their risk of exposure to travel related illness, especially malaria, despite not having lived in an endemic area for many years. ${ }^{10}$ This is a dangerous presumption. Other reasons for the reported increase include inaccessibility of travel health advice, over the counter purchase of inappropriate prophylaxis, and purchase of inexpensive (and sometimes counterfeit ${ }^{11}$ ) prophylaxis at the destination.

Substantial improvements in malaria prophylaxis have aided compliance greatly. Health Protection Agency figures on stated malaria prophylaxis in imported malaria cases together with prescription data over the same four year period suggest that travellers prescribed atovaquone plus proguanil are less likely to contract malaria than those given mefloquine or doxycycline (JN Zuckerman, unpublished data).

Smith and colleagues report a significant decrease in imported cases of $P$ vivax after travel to the Indian subcontinent, a result of successful vector eradication in many urban areas. Pursuing a similar policy and achieving the millennium goals in Africa may reduce the incidence of malaria in endemic areas and improve the health of populations, while also reducing the risk of malaria to travellers, all of which may negate the necessity for prophylaxis in the future.

What else can we do? Healthcare practitioners involved in advising travellers about preventing malaria should follow the clear and concise guidelines on malaria prevention for UK travellers. ${ }^{12}$ Studies of people visiting friends and relatives aimed at identifying the pertinent factors such as cultural beliefs, knowledge, and attitude towards malaria prevention would help understand how best to impart health education through targeted communication and the use of innovative techniques.

1 World Health Organization. World malaria report 2005. 2005. www.rbm. who.int/wmr2005/index.html.

2 World Tourist Organisation. Tourism 2020 vision report.www.pub.unwto. org:81/WebRoot/Store/Shops/Infoshop/Products/1184/1184-1.pdf.

3 Smith AD, Bradley DJ, Smith V, Blaze M, Behrens RH, Chiodini PL, et al. Imported malaria and high risk groups: observational study using UK surveillance data 1987-2006. BM/ 2008;337:a120.

4 Health Protection Agency. Malaria imported into the United Kingdom in 2007: implications for those advising travellers. Health Protection Report. Vol 2. No 17. 2008. www.hpa.org.uk/hpr/archives/2008/ hpr1708.pdf.

5 Office for National Statistics. Overseas travel and tourism. 2008. www. statistics.gov.uk/cci/nugget.asp?id=352.

6 World Health Organization. World health report 2007-a safer future: global public health security in the 21st century. 2007. www.who.int/ whr/2007/en/index.html.

7 Health Protection Agency. Migranthealth: infectious diseases in non-UK born populations in England, Wales and Northern Ireland. A baseline report 2006. London: HPA, 2006. www.hpa.org.uk/web/HPAwebFile/ HPAweb_C/1201767922096.

8 Mühlberger N, Jelinek T, Gascon J, Probst M, ZollerT, Schunk M, et al. Epidemiology and clinical features of vivax malaria imported to Europe: sentinel surveillance data from TropNetEurop. Malaria J 2004;3:5.

9 Loutan L. Migrants: new travelers in a mobile world? Rev Prat 2007;57:861-6.

10 Fulford M, Keystone JS. Health risks associated with visiting friends and relatives in developing countries. Curr Infect Dis Rep 2005;7:48-53.

11 Bate R, Coticelli P, Tren R, Attaran A. Antimalarial drug quality in the most severely malarious parts of Africa-a six country study. PLOS ONE 2008;3:e2132 doi: 10.1371/journal.pone.000132.

12 Chiodini P, Hill D, Lalloo D, Lea G, Walker E, Whitty C, et al. Guidelines for malaria prevention in travellers from the United Kingdom 2007. London: Health Protection Agency. www.hpa.org.uk/web/HPAwebFile/ HPAweb_C/1203496943523.

\section{Genetic engineering in athletes}

\section{Safeguards are needed before the hypothetical threat becomes a reality}

\section{Dominic Wells professor,} Department of Cellular and Molecular Neuroscience, Imperial College, London W12 ONN d.wells@imperial.ac.uk Competing interests: None declared.

Provenance and peer review: Commissioned; not externally peer reviewed.

Cite this as: BMJ 2008;337:a607 doi: 10.1136/bmj.a607
Athletes who want to maximise their performance are continually tempted to use illegal drugs to gain competitive advantage and to aid recovery from training and injuries. Recent revelations of widespread doping arising from investigations of the distribution of the anabolic steroid tetrahydrogestrinone by the American company BALCO (Bay Area Laboratory Co-operative) demonstrate the extent of this problem in world class athletes. ${ }^{1}$

Some commentators have raised concerns that genetic modification or "gene doping" will be the next step in the search for enhanced performance..$^{2-5}$ These concerns are based on some impressive studies in genetically modified rodents where manipulation of individual genes has increased muscle mass, muscle strength, or running endurance, depending on the gene that was manipulated. Reviews of these animal studies conclude that such genetic manipulations could also improve human athletic performance. ${ }^{6} 7$

How likely is it that athletes will use genetic modification? About $10 \%$ of athletes have used existing drugs, ${ }^{8}$ so it is likely that some will be tempted to experiment with genetic modification. However, translating studies performed in rodents into effective treatments in humans will not be easy. Some of the rodent studies were performed in transgenic mice in which the genetic modification was introduced into the germline and transmitted from one generation to the next. For practical and ethical reasons it is not possible to do this in humans.

Widespread genetic modification of somatic rather than germline tissues can be achieved in mice by using modified viruses to deliver the genetic modification, but only when used at very high doses. Scaling up such doses from a $25 \mathrm{~g}$ mouse to a $75 \mathrm{~kg}$ human will prove challenging, both in terms of the facilities needed to generate such viral vectors and the potential difference in immune responses to such viruses between mice and humans. It is also not known how well these vectors will work in humans.

Current clinical trials-for example, those targeted at muscular dystrophies-use only small amounts of these viral vectors, and they are early stage safety trials that will not tell us whether we can achieve the high efficiencies needed to improve muscle function. ${ }^{9}$ It will be many years before agents for gene therapy are available for general clinical use. 
Could black market laboratories generate the necessary viral vectors? Many laboratories can make small amounts suitable for cell cultures and a few experiments in mice, but it would be a major logistical exercise to produce high quality preparations in bulk. If this were possible, athletes would be running considerable risks. Activation of the innate immune system by a relatively high dose of viral vector caused the death of a patient in a clinical trial in 1999. The man, who had ornithine transcarbamylase (OTC) deficiency, developed disseminated intravascular coagulation and organ failure after a delivery of a relatively high dose of recombinant adenovirus carrying the OTC gene into the hepatic artery. ${ }^{10}$

Interfering with genes that could increase athletic performance carries substantial health risks. For example, high levels of growth hormone and insulin-like growth factor-I have been associated with the development of cancers, and overexpression of erythropoietin can lead to stroke and heart failure. Other genes such as those regulating specific aspects of muscle physiology have not been studied for long enough to know what health risks might be associated with their long term use.

What needs to be put in place in anticipation of potential gene doping? Athletes will be less tempted to consider it if tests are in place that could potentially detect such genetic modification. Some aspects that are specific to gene doping make detection more likely, even without the use of complicated diagnostic tests. Firstly, proteins expressed in the athlete after gene transfer are sometimes different from the normal protein. For example, erythropoietin is normally produced in the kidney and stimulates red blood cell production, but after transfer of the erythropoietin gene into muscle changes in the post-translational modification of the protein would enable doping to be detected..$^{11}$

Secondly, athletes are aware of the time needed for current performance enhancing drugs to clear from the system, which is why testing outside of competitions is so important in the fight against doping. One of the disadvantages of gene doping is that it will be more difficult for athletes to tailor their treatments to avoid detection. Thirdly, although gene expression can be controlled after gene transfer, this requires the use of drugs that can readily be detected. Other approaches that are being investigated are the development of a sensitive test for transgenic DNA and protein or gene profiling of athletes over their competitive lifetime. ${ }^{12}$

Although at present gene doping is a threat rather than a reality, it is important to put safeguards in place that will prevent athletes from being tempted not only to cheat but to put their health at substantial risk.

1 Slater M. Graham found guilty in Balco case. BBC Sport 29 May 2008. http://news.bbc.co.uk/sport1/hi/athletics/7425458.stm.

2 Sweeney HL. Gene doping. Sci Am 2004;291:62-9.

3 Schneider Al, Friedmann T. Gene doping in sports: the science and ethics of genetically modified athletes. Adv Genet 2006;51:1-110.

4 Filipp F. Is science killing sport? Gene therapy and its possible abuse in doping. EMBO Rep 2007;8:433-5.

5 World Anti-doping Agency. WADA gene doping symposium calls for greater awareness, strengthened action against potential gene transfer misuse in sport. 2008. www.wada-ama.org/en/newsarticle. ch2?articleld $=3115626$.

6 Baoutina A, Alexander IE, Rasko JE, Emslie KR. Potential use of gene transfer in athletic performance enhancement. Mol Ther 2007;15:1751-66.

7 Wells DJ. Gene doping: the hype and the reality. BrJ Pharmacol 2008;154:623-31.

8 Slater M. Chambers to deliver drugs dossier. BBC Sport 15 May 2008. http://news.bbc.co.uk/sport1/hi/olympics/athletics/7400566.stm

9 Muntoni F, Wells D. Genetic treatments in muscular dystrophy. Curr Opin Neurol 2007;20:590-4.

10 Raper SE, Chirmule N, Lee FS, Wivel NA, Bagg A, Gao GP, et al. Fatal systemic inflammatory response syndrome in an ornithine transcarbamylase deficient patient following adenoviral gene transfer. Mol Genet Metab 2003:80:148-58.

11 Lasne F, Martin L, de Ceaurriz J, Larcher T, Moullier P, Chenuaud $P$. Genetic doping with erythropoietin CDNA in primate muscle is detectable. Mol Ther 2004;10:409-10.

12 Baoutina A, Alexander IE, Rasko JE, Emslie KR. Developing strategies for detection of gene doping. J Gene Med 2008;10:3-20.

\section{Antipsychotics for people with dementia}

\section{Should be reserved for severe and persistent symptoms after assessment of risk and benefit}

\begin{abstract}
John O'Brien professor of old age psychiatry, Wolfson Research Centre, Newcastle General Hospital, Newcastle upon Tyne NE46BE

j.t.o'brien@ncl.ac.uk

Competing interests: JO'B has received honorariums and

hospitality from the manufacturers of drugs mentioned in this

editorial (olanzapine, risperidone,

cholinesterase inhibitors, and memantine). He was a member of the NICE/SCIE Dementia Guideline Development Group.

Provenance and peer review: Commissioned; not externally peer reviewed.
\end{abstract}

Cite this as: $B M J$ 2008;337:a602 doi: 10.1136/bmi.a602
More than 25 million people worldwide have dementia, with a new case developing every seven seconds. ${ }^{1}$ While putative disease modifying agents are being developed, we are limited to symptomatic treatments for cognitive and non-cognitive features. Non-cognitive symptomsreferred to as behavioural and psychological symptoms of dementia-including agitation, psychosis, depression, and aggression, occur in up to half of those with dementia in the community and an even higher proportion in residential care. Antipsychotics have been widely prescribed off licence for these symptoms, and 20-50\% of people with dementia in institutional care receive them. ${ }^{2}$ What is the evidence for their efficacy?

Several placebo controlled, randomised controlled trials (RCTs), especially of newer "atypical" antipsychotics like risperidone, show an improvement in agitation, aggression, and psychosis. ${ }^{3}$ But, even before current concerns over their side effects, the strength of the evidence supporting widespread prescribing in dementia was questioned. Efficacy is modest, and most studies have assessed behavioural and psychological symptoms of dementia as a general outcome rather than targeting specific symptoms.

Side effects include extrapyramidal features, sedation, metabolic disturbances, increased cognitive impairment, and severe sensitivity reactions in dementia with Lewy bodies. In 2004 it emerged that the risk of cerebrovascular events and stroke was three times higher in people treated with the atypicals olanzapine and risperidone. A subsequent meta-analysis showed increased mortality in people treated with atypical antipsychotics compared with placebo, with a number needed to harm of around $100 .{ }^{4}$

These findings combined with high prescribing rates 
for people with dementia led to warnings about the use of these drugs in many countries. In the United Kingdom, the Committee on Safety of Medicines went further than most to advise that "risperidone or olanzapine should not be used for the treatment of behavioural symptoms of dementia." Subsequently, patients had their drugs withdrawn or were switched to typical antipsychotics, often without considering individual circumstances. This led to further guidance from professional organisations supporting the continued use of atypical antipsychotics in some circumstances. ${ }^{6}$

So where are we now? Cohort studies suggest that typical antipsychotics have a similar cerebrovascular risk to atypical antipsychotics, and possibly even higher mortality. ${ }^{7}$ So switching from atypical antipsychotics to typical antipsychotics is unlikely to be a sensible strategy. Questions over efficacy remain. A large pragmatic double blind placebo controlled trial, using an outcome measure of "time to treatment discontinuation," found that the benefits of atypical antipsychotics on efficacy were largely offset by discontinuation because of side effects. ${ }^{9}$

A recent RCT showed that antipsychotics can be safely withdrawn in many people with dementia who have taken them for prolonged periods, especially if symptoms have largely resolved. ${ }^{10}$ Staff and environmental factors are important, and targeted training and support reduced the use of antipsychotics from $42 \%$ to $23 \%$ over one year. ${ }^{2}$

What are the alternatives to antipsychotics? Nonpharmacological approaches are often rightly advocated. Indeed, careful assessment for comorbid conditions and exacerbating factors-including physical illness, pain, communication difficulties, and depression-are an essential part of assessment of behavioural and psychological symptoms of dementia. For milder symptoms, watchful waiting combined with simple explanation, advice, and support may be sufficient. Increased social stimulation or personalised music may help, and aromatherapy has some evidence base.

However, all these non-pharmacological approaches are limited, not only by lack of studies but by the difficulties in undertaking truly placebo controlled trials, combined with an absence of studies in more severe behavioural disturbance. ${ }^{11}$ Cholinesterase inhibitors may be useful for symptoms such as apathy and psychosis, consistent with cholinergic deficit as a likely neurochemical cause. Initial reports that they may reduce agitation, a common and problematic symptom for which antipsychotics are often prescribed, were not confirmed by a large non-industry funded RCT, which showed no benefit of donepezil over placebo. ${ }^{12}$ Post hoc analysis of trials of memantine, an NMDA (N-methyl D-aspartate) antagonist, suggest possible benefits on agitation and aggression. ${ }^{13}$ Evidence for other drugs is limited; carbamazepine may help agitation and aggression, but no clear consensus exists on the role of antidepressants in managing behavioural and psychological symptoms of dementia.

What conclusions can we draw? Evidence based alternatives to antipsychotics are relatively few and limited to people with mild to moderate symptoms. In more severe cases no treatment or non-evidence based treatment is often not a clinical option. Antipsychotics, especially atypical ones, have the best evidence base, although their efficacy is more modest than previously supposed and their side effects more serious. Prescribing rates of up to $50 \%$ for people in residential care cannot be justified. However, given the lack of suitable alternatives, it is not reasonable to stop prescribing completely.

Current advice, such as that contained in the National Institute for Health and Clinical Excellence guidelines for dementia, is pragmatic and helpful. Management of the symptoms consists of a thorough assessment, to search for any modifiable causes. Non-pharmacological approaches should be used first, and possible alternatives-like carbamazepine for aggression, cholinesterase inhibitors for apathy and psychosis, and memantine for agitation-should be considered. Prescription of antipsychotics should be carefully targeted, time limited, and reserved for severe and distressing symptoms after careful assessment of risk and benefit. This is not easy. How, for example, can we weigh up a small but real increased risk of a stroke compared with the possible benefit of remaining in a less restricted environment (for example, at home)? These complex decisions have to involve the patient, where possible, together with the family and carers.

1 Ferri CP, Prince M, Brayne C, Brodaty H, Fratiglioni L, Ganguli M, et al. Global prevalence of dementia: a Delphi consensus study. Lancet 2005;366:2112-7.

2 Fossey J, Ballard C, Juszczak E, James I, Alder N, Jacoby R, et al. Effect of enhanced psychosocial care on antipsychotic use in nursing home residents with severe dementia: cluster randomised trial. BMJ 2006;332:756-61.

3 Katz I, de Deyn P-P, Mintzer J, Greenspan A, Zhu Y, Brodaty H. The efficacy and safety of risperidone in the treatment of psychosis of Alzheimer's disease and mixed dementia: a meta-analysis of 4 placebo-controlled clinical trials. Int / Geriatr Psychiatry 2007;22:475-84.

4 Schneider LS, Dagerman KS, Insel P. Risk of death with atypical antipsychotic drug treatment for dementia: meta-analysis of randomized placebo-controlled trials [see comment]. JAMA 2005;294:1934-43.

5 Committee on Safety of Medicines. Atypical antipsychotic drugs and stroke. London: Department of Health, 2004. www.info.doh.gov.uk/ doh/embroadcast.nsf/vwDiscussionAll/3D8DBB48B26FF90280256E 520045977A.

6 Royal College of Psychiatrists Faculty of the Psychiatry of Old Age. Atypical antipsychotics and BPSD. Prescribing update for old age psychiatrists. 2004. www.rcpsych.ac.uk/pdf/Atypicalguidance.pdf.

7 Gill SS, Rochon PA, Herrmann N, Lee PE, Sykora K, Gunraj N, et al. Atypical antipsychotic drugs and risk of ischaemic stroke: population based retrospective cohort study. BMJ 2005;330:445.

8 Gill SS, Bronskill SE, Normand S-LT, Anderson GM, Sykora K, Lam K, et al. Antipsychotic drug use and mortality in older adults with dementia [summary for patients in Ann Intern Med 2007;146:152]. Ann Intern Med 2007;146:775-86.

9 Schneider LS, Dagerman K, Insel PS. Efficacy and adverse effects of atypical antipsychotics for dementia: meta-analysis of randomized placebo-controlled trials. Am J Geriatr Psychiatry 2006;14:191-210.

10 Ballard C, Margallo Lana M, Theodoulou M, Douglas S, McShane R, Jacoby $R$, et al. A randomised, blinded, placebo-controlled trial in dementia patients continuing or stopping neuroleptics (the DART-AD trial). PLoS Med 2008;5:e76.

11 Ayalon L, Gum AM, Feliciano L, Arean PA. Effectiveness of nonpharmacological interventions for the management of neuropsychiatric symptoms in patients with dementia: a systematic review. Arch Intern Med 2006;166:2182-8.

12 Howard RJ, Juszczak E, Ballard CG, Bentham P, Brown RG, Bullock R, et al. Donepezil for the treatment of agitation in Alzheimer's disease [see comment]. NEngl J Med 2007;357:1382-92.

13 Gauthier S, Wirth Y, Mobius HJ. Effects of memantine on behavioural symptoms in Alzheimer's disease patients: an analysis of the neuropsychiatric inventory (NPI) data of two randomised, controlled studies. Int J Geriatr Psychiatry 2005;20:459-64. 


\section{Enhancing the quality and transparency of health research EQUATOR is an essential web resource for researchers, editors, and readers}

\begin{abstract}
Trish Groves deputy editor, BMJ, London WC1H 9JR tgroves@bmj.com

Competing interests: The BMJ Group sponsored the EQUATOR launch meeting and has

sponsored consensus meetings to develop the CONSORT statement.

Provenance and peer review: Commissioned; not externally peer reviewed.
\end{abstract}

Cite this as: $B M J$ 2008;337:a718 doi: 10.1136/bmj.a718
A young woman, just making ends meet and coping with four children, signed up to a breast cancer study where she would have to take two big pills every day for two years and show up for numerous frequent tests. Why would she put herself through that, wondered the researcher who went to obtain her consent. "I'm doing it for my daughter" said the mother, clearly expecting the study to yield usable, meaningful, and accessible evidence that might help prevent breast cancer in young women. Would she have consented so readily if she knew that some studies are never published and that many are reported so poorly that they are barely read and never used? This tale was told by that same researcher, Davina Ghersi, coordinator of the World Health Organization international clinical trials registry, ${ }^{1}$ at a meeting in London last month. Dr Ghersi was there to help launch the EQUATOR (enhancing the quality and transparency of health research) international network, which seeks to improve the quality of scientific publications by promoting transparent and accurate reporting of health research.

Registration, publication, and publicly available reporting of health research are already mandated by several sponsors and funders, ${ }^{2}{ }^{3}$ some legislators, ${ }^{4}$ and many editors, ${ }^{5}$ particularly for clinical trials. The next big challenge is to decide when and how to disclose the results of a trial at a publicly available research registry, and what should go into a minimum dataset. ${ }^{6}$ Yet even journals, some of which have reported research for many decades, are still not producing articles that are clear enough to really judge a study's conduct, quality, and importance-let alone to allow other researchers to reproduce it or build on it. With help from EQUATOR, journals should now be able to do a much better job and give authors the specific guidance they need to write up research properly.

Editors already provide instructions to authors, but this advice tends to be either unhelpfully vague and brief or comprehensively long and daunting-for instance, the $B M$ Js advice currently extends to well over 20000 words (http://resources.bmj.com/bmj/authors). The development of more than 80 guidelines for reporting different study types, many of them labelled by acronyms, adds to the confusion. Do authors know where to find these guidelines, and do editors and reviewers know how to use them? Do you know your MOOSE (meta-analysis of observational studies in epidemiology) from your STROBE (strengthening the reporting of observational studies in epidemiology)?

The EQUATOR website (www.equator-network. org/) comes to the rescue with a digital library of links to reporting guidelines. These guidelines give point by point advice that enables researchers to say what they did and didn't do in their study, how they did it, and what they found, thus allowing honest discussion of the study's meaning, strengths, and weaknesses. As well as explanatory documents, these guidelines usually incorporate one or two tools-a checklist of items that must be reported clearly, and a template for a flow chart to show what happened to participants at each stage of the study.

The oldest and best known of the current guidelines is the CONSORT (consolidated standards of reporting trials) statement. This has spawned several extensions for different types and aspects of randomised controlled trials, and a plethora of other guidelines have now been developed by consensus groups of experts. The EQUATOR team has identified these guidelines through systematic literature searches, has pulled them together in one place, and has grouped them simply by type of study-including experimental studies, observational studies, systematic reviews, qualitative research, economic evaluations, quality improvement studies, and industry sponsored studies.

This is a real boon for the researcher, reviewer, or editor with a desire for clarity but a poor memory for acronyms. EQUATOR is a good resource for readers and learners too. Although these reporting guidelines are not explicitly intended to be critical appraisal tools, anyone running a journal club or sitting an exam that might test research skills should also find them useful. And the digital library is just the start of a comprehensive programme of work on knowledge translation. Over the next five years the EQUATOR network plans to develop much fuller online resources, including training materials for guideline developers, authors, reviewers, and editors, as well as published articles about improving the reporting of research. The network also aims to audit, every year for the next five years, the quality of reporting in health research and the performance of journals in implementing these guidelines.

The $B M J$ is actively supporting the EQUATOR initiative. We ask researchers to prepare each research article in line with the appropriate reporting guideline and to submit each manuscript with the right checklist properly completed and, if necessary, the right flow chart (http://resources.bmj.com/bmj/authors/types-ofarticle/research) (see box on bmj.com). We will not send a research article for external peer review without these, thus giving our policy some teeth and helping reviewers to understand the study's conduct and quality

Editors should not, however, use these reporting guidelines to reject studies that do not reach some fixed or arbitrary threshold for quality. In difficult and new areas of research, imperfectly conducted studies often provide good enough evidence to change policy or practice or to inform the next phase of research. Such studies deserve to be published, warts and all, but reporting guidelines point out where the warts are and how big they are. Using another bodily metaphor, Ian Needleman, director of London's International Centre for Evidence-based Oral Health, said at the EQUATOR launch "research reporting is too often like swimwear: what it reveals is suggestive; what it conceals is vital."

All references are on bmi.com 